\title{
Inventive Techniques of Teaching English Language
}

\section{M.Mareeswari}

\begin{abstract}
This paper investigates the inventive and very intriguing techniques we have in showing English language We may have various showing techniques in the middle of customary and current. Everyone has their own comprehension and ends on showing English dialect. Yet, this paper depicts consolidating these two sorts how we can make our showing exceptionally powerful. We have been totally limited with customary strategies for instructing and accepting where the present day students experienced awkward a bit. Student's psyche will not at all be static it is consistently developing and regularly evolving. At all the instructing technique is capable to be, yet encouraging should be more slanders focused. Be that as it may, this paper investigates the contrast among customary and reasonable instructing and from that point learning. This treatise essentially looks at that how students are being influenced by the conventional strategies for educating also, other than it has depicted that how students imagine instructing and learning method. There has been a misconception stuck between customary strategies and pragmatic techniques dependably. Some way or another educators and students ought to concur one another keeping in mind the end goal to fill the hole between the ages of these strategies.
\end{abstract}

Keywords: Awkward, Concur, Conventional, Misconception, Strategies.

\section{INTRODUCTION}

$E_{\text {nglish, the official language of the whole world is a }}$ really dubious language to educate. Truth is, each vernacular differs to teach. English is an excellently old dialect and has practiced numerous structures transformed from Proto English acquired from the Latin and the German culture to the contemporary English which was built up next in the post Renaissance period. Every variant be there less difficult than its past. Modern English is the most straightforward adjustment of an exceptionally old Language but it is as yet hard to show this dialect viably particularly to the individuals who communicate in English as a second dialect.

\section{ISSUES WITH CURRENT TECHNIQUES}

In the present day English is instructed in an extremely universal way. The essential instructing is required. Encouraging the letter sets and the arrangement of the words is basic and an unquestionable requirement.

Revised Manuscript Received on December 20, 2019.

M.Mareeswari*, Department of English, Kalasalingam Academy of Research and Education, Krishnankovil, Virudunagar, Tamilnadu, India.
In any case, there is something that is significantly more vital. The youngsters must have the capacity to talk the words and comprehend their significance before thinking of them down. The establishment to train English must be shown utilizing the customary techniques for showing the letter sets and the words and the guidelines. Yet, at that point showing just the tenets is observed to exhaust by most understudies and it is a direct result of this that they lose enthusiasm for taking in the dialect. Despite the fact that it is highly unlikely other than the customary one to show the nuts and bolts of the dialect these strategies must be changed a bit in order to speak to the understudies. With regards to instructing English to understudies of advanced module who definitely recognized the nuts and bolts the customary strategies for the most part tend to yield poorer outcomes that imaginative techniques. This has just been demonstrated by strategies actualized like utilization of stories, lyrics, motion pictures, books and daily papers and so forth. These strategies enable the understudies to take in the dialect enhanced devoid of them really acknowledging and furthermore it maintains their improvement. This document will give a couple of such strategies to enlighten English Language.

\section{ENACTING THE STORIES}

Stories shape an extremely basic piece of showing a dialect. These accounts help show the understudies the improvement of sentences and how to communicate their contemplations as well as a great deal of different items and in addition to the facilitate in caring the understudies intrigue animate as the story's last part is something with the intention of each understudy needs to identify. It proceeds to the curious thought of the understudies. In the least incomplete story dependably keeps the mind of the peruse disturbed.

Despite the fact that this strategy for utilizing stories has been executed the system of training the dialect through it is for the most part not right. The assessment system of testing the understudies in their capability over the dialect is through inquiries in view of the story. This is by and large not so compelling. Because of this the understudies for the most part tend to take up the narratives as a section instead of taking a gander at it as a fascinating read. A story guessed request to the inventive piece of the cerebrum. It pushes us be alive more innovative, as a result of attempting to picture the effects that are going on within the story. It ought show them the dialect as well as help them in separating an exercise from the story. Keeping inquiries for assessment murders the whole thought of creative ability for the understudies acquire 
a gander at the story as something that they have to discover for answers.

There is a superior method for utilizing the narratives to English utilizing stories. The understudies can authorize the accounts or the plays. Along these lines the understudies are actually drawn in with the accounts. They can convey their personal translation of the spirit to life. It is fascinating for the understudies to comprehend the characters and place themselves in their positions. It connects with their innovativeness by enabling them to make the whole set, dole out the characters and play it out as per what they had envisioned. It likewise causes them comprehend different people's understanding of the story and encourages them have a sound discussion about it which again encourages them in taking in the dialect. It expels the dull perspectives and makes the adjusting more brilliant without imperiling the learning of the language. It may not be flawless but rather it will leave a reflective impact at the forefront of their feelings.

The story will permit them to take in the vernacular as they will found it by discourse which they will themselves separate from the accounts and furthermore alterations can be prepared to the plays to enable the understudies to be more intuitive and imaginative. It can include more lines, characters, change the consummation, and acquire a fascinating turn and so on. The more imaginative the change, more are the focuses granted to the group. This likewise prompts identity advancement and encourages them fill in as a cooperative person and the distance the understudy was taking in the dialect.

For instance if Julius Caesar was shown utilizing the conventional techniques for inquiries and answers the understudy could never comprehend the profound feelings of Brutus, the guile of Cassius, the reliability of Antony, the deplorability of war, the splendor in Antony's discourse and numerous other such parts of the story for which the narrative of Julius Caesar was composed by Shakespeare. Comparative is the situation with every single extraordinary story, for example, Christmas Carol, Harry Potter, and all the epic stories. Feelings aid characterizes the story and they frame a critical part of the dialect and one's identity. On the off chance that these feelings are forgotten then it would be exceptionally hard to convey what needs be. Then again if such stories are authorized then every goal of the story turns out to be clear. The understudies need to inundate themselves into the climate of the story and they need to place them in their positions. This whole procedure has numerous advantages other than being an extremely viable technique for showing the dialect; it helps protect the writing, which is only our way of life. This technique realizes the aggregate learning knowledge that was intended to be given by the story and at last the understudy will have the capacity to answer inquiries without getting ready for it as an exam, other than the whole procedure is fun and not in any manner exhausting. Consequently it guarantees the learning procedure is finished.

\section{INSTRUCTING THROUGH CONVERSATION}

Discussions are by a long shot the most valuable methods for showing the dialect. At the point when a tyke takes in his or her first language it is as a result of the discussions with the aim of happens among them and others or by tuning in to the discussions made by the others. The kid is not at all encouraged the dialect. It prepared to percept the importance and learns it consequently to utilize it into everyday existence. Nobody yet shows the child the characters of the dialect or how to build sentences or the punctuation of that language. The discussions in parallel show the youngsters.

Consequently discussions frame an essential piece of the instructing procedure. The sentence development and the language isn't something that can be altogether educated by tenets. They must be educated naturally. That can just occur through a ton of perusing and a considerable measure of tuning in. This can be dealt with effortlessly as each discussion needs a subject. The theme can be given to the understudies in type of composed records which they need to initially read at that point frame a conclusion and afterward have a discussion about it or it very well may be stood up and after that they can tune in, comprehend and furthermore partake in the discussion.

The support and different parts of the discussion can simply be accessed through focuses which will likewise push the understudies to participate in the discussion. These discussions must be general. They need to occur as though companions are conversing with one another. Thusly the understudies are agreeable in conveying everything that needs to be conveyed in the most ideal way. This procedure may take some time yet at last it would be the most productive one in showing the dialect.

\section{CONCLUSION}

The dialects assume an imperative job in our lives. They enable us to communicate our feelings. They enable us to clarify what we need. They assist us with communicating and consequently are the main devices to convey our uniqueness. Hence the learning of a dialect and its legitimate use is critical as it characterizes us. On the off chance that dialects were not there to enable us to convey there would be no distinction in our interchanges and the manner in which the creatures impart. Thus the manners in which the dialects are shown assume an exceptionally essential job in a person's existing.

In view of the fact that English is the official dialect of this globe it is of most extreme significance that this dialect must be instructed so that it will help us not simply to talk and compose and tune in but rather to convey. That is the reason for the dialect and that is the thing that it must be utilized for. Henceforth inventive strategies help in communicating a transform and the mainstream of the occasions to improve things. It enables the understudies to learn quicker and in a productive, fascinating and an intuitive way and it is the educator's obligation to go the conventional techniques and clear a path for 
innovative and improved strategies for the understudy's advantage.

\section{REFERENCES}

1. Constance Leuenberger, The New Kindergarten: Teaching Reading, Writing, \& More, Publisher: Teaching Resources, August 11, 2003

2. Edgar H. Schuster, Edgar H. Schuster, Breaking the Rules Liberating Writers Through Innovative Grammar Instruction, Heinemann; February 13, 2003

3. Kevin D. Besnoy, Lane W. Clarke, High-Tech Teaching Success! A Step-by-Step Guide to Using Innovative Technology in Your Classroom, Prufrock Press, Inc. October 1, 2009

4. Judith S. Gould, Evan Jay Gould, Judy Mitchell, Mary Rojas, Four Square Writing Method : A Unique Approach to Teaching Basic Writing Skills for Grades 1-3,

5. Lynne T. Diaz-Rico, Teaching English Learners: Strategies and Methods Marlene D. LeFever, Creative Teaching Methods, Cook Ministry Resources; March 1, 1997

6. Nicholas McGuinn,David Stevens, The Art of Teaching Secondary English: Innovative and Creative Approaches, Routledge; August 7, 2004

7. Paul Nation, New Ways in Teaching Vocabulary (New Ways in Tesol Series: Innovative Classroom Techniques); TESOL, January 1 , 1995

8. Patrick Schwarz, Paula Kluth You're Welcome: 30 Innovative Ideas for the Inclusive Classroom; Heinemann, August 17, 2007

9. R. Patrick Solomon, Dia N. R. Sekayi, Urban Teacher Education and Teaching: Innovative Practices for Diversity and Social Justice, Routledge; March 30, 2007

10. Susan Van Zile, Awesome Hands-on Activities for Teaching Grammar, Teaching Resources; December 1, 2003

\section{AUTHORS PROFILE}

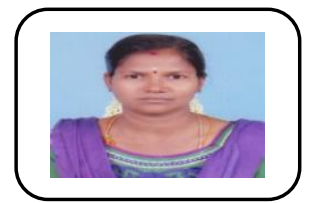

M. Mareeswari, A ssistant Professor, Department of English, Kalasalingam Academy of Research and Education, Virudhunagar, Tamil Nadu- India 